\title{
Breastfeeding and maternal medications
}

\author{
Roberto G. Chaves, ${ }^{1}$ Joel A. Lamounier ${ }^{2}$
}

\begin{abstract}
Objective: To contribute with information about the adequate administration of drugs during breastfeeding.

Sources of data: MEDLINE articles from 1993 to 2004, and Lilacs articles from 1995 to 2004 were selected in Portuguese, Spanish and English, by including the following keywords: breastfeeding, lactation, drugs and medicines. Other update references found in articles and books were also included in this review, in order to provide additional information.

Summary of the findings: Most of the drugs are compatible with breastfeeding. Few were considered inadequate, such as antineoplastic drugs, radiopharmaceuticals and drugs of abuse. Some drugs require concern, as they may cause adverse effects in breastfed babies or reduce the mother's breast milk volume. However, further knowledge on some medicines during lactation is required.

Conclusion: The fundamental principle in the prescription of medicines for lactating mothers is mostly based on the concept of risk and benefit. The option must be, as much as possible, for a drug that has already been studied, which is little released in the maternal milk or that does not mean an apparent risk for the infant's health. Medicines that reduce the mother's production of milk should be avoided during the lactation period. The use of galactogogos is reserved for particular situations. Therefore, only safety drugs should be administered during breastfeeding, which should rarely be discouraged or discontinued in such cases.
\end{abstract}

J Pediatr (Rio J). 2004;80(5 SuppI):S189-S198: Breastfeeding, lactation, drugs.

Breastfeeding is associated with nutritional, immunological, emotional, economic and social benefits. Therefore, it is of paramount importance that the factors that lead to early weaning be identified so as to provide infants with as long a breastfeeding period as possible. ${ }^{1}$

Several studies confirm that among the factors that lead to early weaning are problems related to the risk of infant exposure to maternal medications. ${ }^{2-4}$ Information and bibliographic references on drugs and breastmilk have been available, but many health professionals, especially physicians, prefer to discontinue breastfeeding, either due to lack of information or lack of interest, to

1 Pediatrician. Assistant professor, School of Physical Therapy, Universidade de Itaúna, MG, Brazil.

2. Ph.D., UCLA, Los Angeles. Full professor of Pediatrics, School of Medicine, Universidade Federal de Minas Gerais (UFMG), Belo Horizonte, MG, Brazil.

Suggested citation: Chaves RG, Lamounier JA. Breastfeeding and maternal medications. J Pediatr (Rio J). 2004;80(5 Suppl):S189-S198. attempting to adjust it with the treatment being received by the mother. ${ }^{5}$ Moreover, the information contained in drug package inserts and the scientific evidence regarding medication use during breastfeeding is often inconsistent. 6,7

Even though the knowledge about medication use during breastfeeding has been largely expanded, the side effects of several drugs used by the mother in breastfed infants are still unknown. ${ }^{8}$ On top of that, the effects of many new drugs have not been sufficiently studied yet ${ }^{8}$ or controversy exists in the literature over their use during breastfeeding. Therefore, it is necessary to be constantly up-to-date with information on medication use during breastfeeding, so that these medications are used in a judicious manner and the breastfeeding practice is guaranteed.

In the present study, we used the publication by the American Academy of Pediatrics (AAP) revised in $2001^{4}$ as basic reference. Although this classification is not yet fully satisfactory, it is one of the most comprehensive and cited publications in the scientific community. 
This is a review article including the most relevant publications on medication use during breastfeeding. Pharmacological aspects that determine drug selection are discussed, and the safest medications and also those that are contraindicated are specified. Moreover, precautions with some medications and the use of galactogogues and lactation suppressants are also discussed. No information was included about the effects of pollutants and chemical contaminants found in water, air or foods on human milk. Although, from the pharmacological standpoint, there may be slight differences in the definition of drug and medication, these terms are interchangeably used in this paper.

\section{Transfer of drugs into breastmilk}

It is essential that health professionals know the factors that determine the safety of the drugs used during breastfeeding. Such factors may be related to breastmilk, to the mother, to the drug or to the infant, as shown in Table 1.

\section{Breastmilk-related factors}

Breastmilk is subject to significant changes in lipid and protein concentrations, which depend upon the stage of lactation (colostrum versus mature milk) or even upon the stage of a breastfeed (foremilk versus hindmilk). Such changes influence how much of a drug is transferred from plasma to milk, causing variations in drug concentration in the breastmilk. ${ }^{9}$

Table 1 - Factors that determine the safety of the drugs used during breastfeeding

\section{Factors related to breastmilk}

Milk composition (lipid and protein concentrations)

Factors related to the mother

Renal and hepatic excretion

Dose and duration of treatment

Route of administration

\section{Factors related to the infant}

Age

Drug absorption

Renal and hepatic excretion

Volume of milk intake

Safety of the drug for the infant

\section{Factors related to the drug}

PKa (dissociation constant)

Solubility in water and lipids

Molecular size

Oral bioavailability

Toxicity

Suppressive effect on milk production

Long-acting drugs $x$ short-acting drugs

\section{Mother-related factors}

During the first days of lactation (colostrum), alveolar cells are small and the intercellular space is large, which makes maternal substances, including drugs, lymphocytes, immunoglobulins and proteins cross more easily into breastmilk. With lower progesterone levels, alveolar cells expand and intercellular spaces become narrow, and consequently, the transfer of drugs and other substances is reduced. However, the volume of milk (colostrum) ingested by the infant on the first days of life ( 50 to $60 \mathrm{ml}$ / d) is low, and therefore the absolute dose of medication transferred to the infant is very low during this period. ${ }^{10}$

Factors that reduce the ability of mothers to metabolize or excrete the drug may increase infant exposure to the drug. ${ }^{3}$ Therefore, special precaution should be taken against prescribing drugs to nursing mothers with liver or kidney diseases due to the elevated levels and increased circulation of the drug in the mother's bloodstream.

The route of administration of the drug to the mother is important because of the high levels reached in maternal plasma and, later on, in human milk. Thus, several drugs administered topically or inhaled do not reach significant serum levels, and therefore their concentrations in the milk cannot be measured. Several antibiotics, corticosteroids and retinoids applied in small areas are not well absorbed through the skin and practically go undetected in the plasma. ${ }^{10}$

\section{Drug-related factors}

Knowing certain characteristics of the drugs and their diffusion through the body may be useful to identify the risk of using these drugs during breastfeeding.

The pharmacokinetics of drugs varies with some milk components and with maternal factors. Their concentration in breastmilk may be influenced by degree of ionization, lipid solubility, protein binding and molecular weight, as described below:

- Molecular weight: drugs with low molecular weight reach breastmilk more easily than those with higher molecular weight. ${ }^{11}$ The membrane pores allow the movement of molecules with molecular weight lower than 200 daltons. Small molecules, such as ethanol, cross the maternal capillary endothelium and the alveolar cell by passive diffusion.

- Degree of ionization: drugs that are weak bases tend to be less ionized in plasma $(\mathrm{pH}=7.4)$ and to remain ionized in the milk compartment $(\mathrm{pH}=7.1)$, which favors their concentration in breastmilk. ${ }^{3,10}$

- Protein binding: drugs with a low affinity for plasma proteins can easily reach the milk compartment. Ex: diazepam.

- Lipid solubility: fat-soluble drugs cross the lipid and protein cell membrane more easily, transferring readily into the milk compartment. They are more commonly found in mature milk due to its higher lipid concentration. Ex: sulfonamides, chloramphenicol.

Adapted from Howard \& Lawrence ${ }^{3}$. 
- Half-life: long-acting drugs maintain circulating levels for a longer period of time in the mother's bloodstream and, consequently, in breastmilk.

Another important aspect is the peak serum levels of the drug. Usually, the peak in the mother coincides with the peak in breastmilk, and is lower in the latter. Thus, it is important to know when the peak serum level of a drug occurs in order to adjust the time of administration of the drug and the breastfeeding time. To prevent the breastfeeding from coinciding with the higher serum concentration of the drug, the drug should be given to the mother immediately after she has breastfed the infant. On top of that, drugs with a long half-life, or which have active metabolites, provide longer infant exposure to the drug.

The oral bioavailability of the drug is very important to assess the risk to the infant. Drugs with low bioavailability and low absorption by the infant can be used during the breastfeeding period. For example, sumatriptan (15\% bioavailable) is preferred to rizatriptan (more than $45 \%$ bioavailable). ${ }^{10}$

Regardless of pharmacological characteristics, drugs that are known to be toxic to infants, such as antineoplastic drugs, radioactive drugs or drugs of abuse, are contraindicated during the breastfeeding period.

Physicians have to bear this information in mind when prescribing any kind of drug to a nursing mother.

\section{Infant-related factors}

The age of the infant should be considered when assessing the possible effects of a drug used by a nursing mother. In newborns, the effects are stronger than in older infants, whose hepatic and renal functions are more efficient. These effects may be even stronger in preterm infants, whose immaturity may extend the half-life of drugs resulting in their accumulation after repeated doses. ${ }^{12}$ Hale classifies infants, according to their ages, as low-risk ( 6 to 18 months), moderate-risk (younger than 6 months) and high-risk (preterm, newborn, clinically unstable infants and those with poor renal function) for the drug of interest. ${ }^{10}$ However, younger infants tend to consume a lower volume of milk than older infants, consequently being less exposed to maternal drugs.

Infants who breastfeed more often and consume a higher volume of milk are more vulnerable to maternal drugs than those who breastfeed less often and ingest a lower volume of milk.

\section{Methods for estimating drug exposure}

After understanding the mechanisms that determine infant exposure to maternal drugs, it is important to know how to measure this exposure. Milk-to-plasma ratio, and absolute and relative infant doses, are widely used for this purpose. These measurements are more important when women use drugs for long periods.

\section{Milk-to-plasma ratio}

Milk-to-plasma ratio is often used to estimate the amount of drug transferred into the milk. It is a ratio between the drug concentration in the plasma and in milk ultrafiltrate at steady state.

Milk-to-plasma ratio $=\frac{\text { drug concentration in milk }}{\text { drug concentration in plasma }}$

This ratio is useful in estimating the relative amount of drug in the milk; in general, a low milk-to-plasma ratio indicates a low drug concentration in milk. However, this ratio should be interpreted carefully, since a ratio greater than one should not cause concern when drug concentration in the maternal plasma is very low or the drug is not absorbed by the infant.3,13 Moreover, although the concentrations of many drugs vary in plasma and in milk, fixed doses are used to calculate the ratio. ${ }^{9}$

\section{Absolute infant dose}

The infant dose can be calculated using drug concentration in milk and the volume of milk ingested:

Absolute infant dose $=$ drug concentration in milk $\mathrm{X}$ volume of milk ingested

The accurate determination of these variables is too difficult to obtain; that is why an estimate is used. Drug concentration in milk can be obtained from clinical trials, but the concentrations of some drugs are still unknown. The volume of milk ingested is estimated at approximately $150 \mathrm{ml} / \mathrm{kg} /$ day. ${ }^{3}$ However, this value may substantially decrease in infants who receive complementary breastfeeding. In practice, when the drug has a well known pediatric use, the absolute infant dose can be directly compared with the normal therapeutic dose for the age in question. ${ }^{9}$

\section{Relative infant dose or percentage of maternal dose}

The estimation of the relative infant dose has been used to assess the safety of drugs during breastfeeding.

\author{
Relative infant dose $(\%)=$ \\ Absolute infant dose $(\mu \mathrm{g} / \mathrm{kg} /$ day $) \times 100$
}

Maternal dose $(\mu \mathrm{g} / \mathrm{kg} /$ day $)$

This value is usually expressed as a percentage of the maternal dose and proposes a standardization of the percentage of maternal dose received by the infant. ${ }^{2}$ It is recommended that the relative infant dose should be less than $10 \%$ so that the drug can be considered safe. ${ }^{13}$ 
However, based on the principle that mother and infant have the same absorption, metabolization and excretion of the drug, this method is not so efficient in determining drug safety during the breastfeeding period. ${ }^{3}$

\section{Classification of drugs for use during breastfeeding}

To guide physicians on the use of drugs during breastfeeding, the AAP has published some recommendations about the transfer of drugs into human milk, the first of which was published in 1983, with revisions in 1989, 1994 and 2001.4

In the latest revision, the AAP presented a new drug classification:

- Cytotoxic drugs that may interfere with cellular metabolism of the nursing infant;

- Drugs of abuse for which adverse effects on the infant during breastfeeding have been reported;

- Radioactive compounds that require temporary cessation of breastfeeding;

- Drugs for which the effect on nursing infants is unknown but may be of concern;

- Drugs that have been associated with significant effects on some nursing infants and should be given to nursing mothers with caution;

- Maternal medication usually compatible with breastfeeding.

Tables 2 to 6 specify the drugs according to the AAP classification. If some drugs do not appear in the tables, it does not mean that they are not found in breastmilk or that they do not produce an effect on infants; it only indicates that there were no reports in the literature.

Although the AAP publication is important to guide health professionals, it fails to include a large number of commonly prescribed drugs and does not discuss relevant practical issues such as safe dose and age of the infant. This omission highlights the importance to have publications that can guide health professionals in a practical and up-to-date manner.

Table 2 - Drugs incompatible with breastfeeding

$\begin{array}{lll}\text { Cyclophosphamide } & \text { Anphetamine } & \text { Cocaine } \\ \text { Cyclosporine } & \text { Methrotrexate } & \text { Heroine } \\ \text { Doxorubicin } & \text { Phencyclidine } & \text { Marijuana }\end{array}$

Table 3 - Drugs that require temporary interruption of breastfeeding

Copper 64 (Cu 64)

Gallium 67 (Ga 67)

Indium 111 (In 111)

Iodine 123 (I 123)
Iodine 125 (I 125)

Iodine 131 (I 131)

Technetium 99 (Tc 99)

Radioactive sodium
Table 4 - Drugs for which the effect on nursing infants is unknown but may be of concern

Anti-anxiety
Alprazolam
Diazepam
Lorazepam
Midazolam
Perphenazine
Prazepam
Quazepam
Temazepam

\section{Antipsychotic}

Chlorpromazine

Chlorprothixene

Clozapine

Haloperidol

Mesoridazine

Trifluoperazine

\author{
Antidepressants \\ Amitriptyline \\ Amoxapine \\ Bupropion \\ Clomipramine \\ Desipramine \\ Dothiepin \\ Doxepin \\ Fluoxetine \\ Fluvoxamine \\ Imipramine \\ Nortriptyline \\ Paroxetine \\ Sertraline \\ Trazodone

\section{Others} \\ Amiodarone \\ Chloramphenicol \\ Clofazimine \\ Lamotrigine \\ Metronidazole \\ Metoclopramide \\ Tinidazole
}

Table 5 - Drugs that have been associated with significant effects on some nursing infants and should be given to nursing mothers with caution

\begin{tabular}{lll}
\hline Acebutolol & Aspirin & Phenindione \\
5-Aminosalicylic acid & Clemastine & Phenobarbital \\
Atenolol & Ergotamine & Primidone \\
Bromocriptine & Lithium & Sulfasalazine
\end{tabular}

In Brazil, about 1,500 active ingredients ${ }^{14}$ are commercialized, but most of them are not investigated as to their transfer into breastmilk and as to their use during breastfeeding. The AAP, in its latest revision, describes only 233 drugs, approximately $15 \%$ of the drugs sold in Brazil, that is, there is a paucity of information about $85 \%$ of the drugs used in breastfeeding mothers in our setting. In addition, the referred publication does not provide any information about safe doses. It is commonly known, for instance, that alcohol and estrogen, considered to be compatible with breastfeeding by the AAP, may decrease the volume of milk in moderate to high doses.

Another factor that is overlooked by the AAP classification is concerned with infant age. In a recent review on infants' adverse reactions to maternal medication, $63 \%$ of the reactions occurred in newborns, $78 \%$ in infants aged less than two months, and only $4 \%$ in infants older than six months. ${ }^{6}$ Therefore, when prescribing drugs to nursing mothers with reported infant adverse reactions, the number of breastfeedings and the maturity of the systems involved in the metabolism and excretion of drugs, which vary considerably with infant age, should be taken into consideration. 
Table 6 - Drugs usually compatible with breastfeeding

\begin{tabular}{|c|c|c|c|}
\hline Acetaminophen & Codeine & Iohexol & Phenytoin \\
\hline Acetazolamide & Colchicine & Iopanoic acid & Piroxicam \\
\hline Acitretin & Contraceptive pill with estrogen/ & Isoniazid & Prednisolone \\
\hline Acyclovir & progesterone & Interferon- & Prednisone \\
\hline Alcohol (ethanol) & Cycloserine & Ivermectin & Procainamide \\
\hline Allopurinol & D (vitamin) & $\mathrm{K}_{1}$ (vitamin) & Progesterone \\
\hline Amoxicillin & Danthron & Kanamycin & Propoxyphene \\
\hline Antimony & Dapsone & Ketoconazole & Propranolol \\
\hline Atropine & Dexbrompheniramine maleate & Ketorolac & Propylthiouracil \\
\hline Azapropazone (apazone) & with $d$-isoephedrine & Labetalol & Pseudoephedrine \\
\hline Aztreonam & Diatrizoate & Levonorgestrel & Pyridostigmine \\
\hline $\mathrm{B}_{1}$ (thiamin) & Digoxin & Levothyroxine & Pyrimethamine \\
\hline $\mathrm{B}_{6}$ (pyridoxine) & Diltiazem & Lidocaine & Quinidine \\
\hline $\mathrm{B}_{12}$ & Dipyrone & Loperamide & Quinine \\
\hline Baclofen & Disopyramide & Loratadine & Riboflavin \\
\hline Barbiturate & Domperidone & Magnesium sulfate & Rifampin \\
\hline Bendroflumethiazide & Dyphylline & Medroxyprogesterone & Scopolamine \\
\hline Bishydroxycoumarin (dicumarol) & Enalapril & Mefenamic acid & Secobarbital \\
\hline Bromide & Erythromycin & Meperidine & Senna \\
\hline Butorphanol & Estradiol & Methadone & Sotalol \\
\hline Caffeine & Ethambutol & Methimazole (active metabolite & Spironolactone \\
\hline Captopril & Ethanol (cf. alcohol) & of carbimazole) & Streptomycin \\
\hline Carbamazepine & Ethosuximide & Methohexital & Sulbactam \\
\hline Carbetocin & Fentanyl & Methyldopa & Sulfapyridine \\
\hline Carbimazole & Fexofenadine & Methyprylon & Sulfisoxazole \\
\hline Cascara & Flecainide & Metoprolol & Sumatriptan \\
\hline Cefadroxil & Fleroxacin & Metrizamide & Suprofen \\
\hline Cefazolin & Fluconazole & Metrizoate & Terbutaline \\
\hline Cefotaxime & Flufenamic acid & Mexiletine & Terfenadine \\
\hline Cefoxitin & Fluorescein & Minoxidil & Tetracycline \\
\hline Cefprozil & Folic acid & Morphine & Theophylline \\
\hline Ceftazidime & Gadopentetic (Gadolinium) & Moxalactam & Thiopental \\
\hline Ceftriaxone & Gentamicin & Nadolol & Thiouracil \\
\hline Chloral hydrate & Gold salts & Nalidixic acid & Ticarcillin \\
\hline Chloroform & Halothane & Naproxen & Timolol \\
\hline Chloroquine & Hydralazine & Nefopam & Tolbutamide \\
\hline Chlorothiazide & Hydrochlorothiazide & Nifedipine & Tolmetin \\
\hline Chlorthalidone & Hydroxychloroquine & Nitrofurantoin & Trimethoprim/sulfamethoxazole \\
\hline Cimetidine & Ibuprofen & Norethynodrel & Triprolidine \\
\hline Ciprofloxacin & Indomethacin & Norsteroids & Valproic acid \\
\hline Cisapride & Iodides & Noscapine & Verapamil \\
\hline Cisplatin & Iodine & Ofloxacin & Warfarin \\
\hline Clindamycin & Iodine (povidone-iodine, eg, in a & Oxprenolol & Zolpidem \\
\hline Clogestone & vaginal douche) & Phenylbutazone & \\
\hline
\end{tabular}

Table 7 contains some up-to-date considerations and recommendations about the use of drugs during breastfeeding, giving special attention to recent publications. The major drug classes are described, and those drugs that are most indicated, contraindicated, or those which should be used cautiously during breastfeeding are listed.

Some information and observations regarding infants under treatment, which may be relevant to the practice of health professionals, have been described by several authors. For instance, in a recent study, Aljazaf et al. 28 showed a significant reduction in the volume of breastmilk after maternal use of pseudoephedrine (60 mg, qid), a drug that is widely used in Brazil as nasal decongestant, combined with antihistamines. This study is a warning against the use of this substance, which is considered to be compatible with breastfeeding by the AAP. Another example is the use of metronidazole, classified by the AAP as a drug for which the effect on nursing infants is unknown but may be of concern, for which cessation of breastfeeding for 12 to 24 hours is recommended. Such concern is due to the theoretical risk of carcinogenesis and high bioavailability. ${ }^{3}$ However, no adverse effects on breastfed infants have been reported so far ${ }^{2}$ and therefore no data supporting the cessation of breastfeeding exist. ${ }^{24}$ With regard to the use of telmisartan - an antihypertensive and an angiotensin II receptor antagonist - during pregnancy, five cases of fetal death and one case of neonatal death (fourth day of life) due to acute renal failure have been reported. Therefore, the authors suggest 
that this drug should be avoided during breastfeeding until new studies are conducted. ${ }^{20}$ Del Ciampo et al. contraindicate bromocriptine and ergotamine during breastfeeding due to the risk of lower milk production, and they also contraindicate the use of quinolones, due to the risk of intoxication and joint involvement. ${ }^{29}$

Owing to the increasingly frequent use of silicone breast implants for breast enlargement or correction, some information may be of great relevance. According to the literature, silicone used for breast enlargement was implanted in approximately one million U.S. women until 2001. Nevertheless, only one study reported esophageal dysfunction in 11 breastfed infants whose mothers had received a breast implant. Other studies have not confirmed these findings. Thus, the AAP considers silicone implants to be compatible with breastfeeding. 4

Table 7 - Recommendations about the use of drugs during breastfeeding

\begin{tabular}{|c|c|c|c|}
\hline Major drug classes & Indicated drugs & $\begin{array}{l}\text { Drugs that should be used } \\
\text { cautiously }\end{array}$ & Reference \\
\hline Anticonvulsivant & Lorazepam, midazolam, diazepam *, nitrazepam * & Alprazolam & 15 \\
\hline Neuroleptics & Sulpiride & $\begin{array}{l}\text { Chlorpromazine, clozapine, } \\
\text { haloperidol, promethazine }\end{array}$ & $2,16,17$ \\
\hline Antidepressive & $\begin{array}{l}\text { Sertraline, paroxetine, citalopram, } \\
\text { moclobenide }\end{array}$ & $\begin{array}{l}\text { Fluoxetine, nefazodone, } \\
\text { bupropion, lithium }\end{array}$ & $2,13,18$ \\
\hline Antiseizure & Phenytoin, carbamazepine $*$, valproic acid & $\begin{array}{l}\text { Ethosuximide, phenobarbital, } \\
\text { primidone }\end{array}$ & 6,15 \\
\hline Opioids & Codeine, propoxyphene, morphine * & Meperidine, methadone & 2,19 \\
\hline $\begin{array}{l}\text { Analgesics and non-steroid } \\
\text { antiinflammatory drugs }\end{array}$ & Paracetamol, ibuprofen, ketorolac, celecoxib & Naproxen, acetylsalicylic acid ${ }^{\dagger}$ & 2,19 \\
\hline Corticosteroids & Prednisone, hydrocortisone, dexamethasone & & 17 \\
\hline Antihistamines & Loratadine, fexofenadine, terfenadine & Promethazine $*$, clemastine & 17 \\
\hline Bronchodilators & Aminophylline, theophylline, salbutamol & & 17 \\
\hline Antihypertensive drugs & $\begin{array}{l}\text { Nifedipine, nimodipine, methyldopa, captopril }{ }^{\neq}, \\
\text {enalapril }{ }^{\ddagger} \text {, propranolol, hydralazine }\end{array}$ & $\begin{array}{l}\text { Atenolol, acebutolol, diuretics, } \\
\text { reserpine, telmisartan }\end{array}$ & $2,17,20,21$ \\
\hline Antiarrhythmic & $\begin{array}{l}\text { Digoxin, verapamil, lidocaine, } \\
\text { procainamide, quinidine }\end{array}$ & Amiodarone & 2,22 \\
\hline Antacid & $\begin{array}{l}\text { Aluminium hydroxide, magnesium hydroxide, } \\
\text { cimetidine }\end{array}$ & Sodium bicarbonate & 17,23 \\
\hline Antiemetic drugs & Domperidone, dimenhydrinate & Metoclopramide & 17,23 \\
\hline Antiparasitic drugs & Albendazole, mebendazole, levamisole, praziquantel & Ivermectin & 17 \\
\hline Antibiotics $\S$ & $\begin{array}{l}\text { Beta-Lactam, macrolide, aminoglycosides, } \\
\text { sulfonamides } 1 \text {, metronidazol, clindamycin }\end{array}$ & $\begin{array}{l}\text { Fluoroquinolones, tetracyclines, } \\
\text { chloramphenicol }\end{array}$ & $17,19,24,25$ \\
\hline Antituberculosis drugs & $\begin{array}{l}\text { Isoniazid, rifampicin, pyrazinamide, } \\
\text { ethambutol, streptomycin }\end{array}$ & Ethionamide & 17,26 \\
\hline Antifungal drugs & Nystatin, miconazole, fluconazol, ketoconazole & Griseofulvin, amphotericin b & 17,27 \\
\hline Antiviral drugs & Acyclovir & Other antiviral drugs & 27 \\
\hline Antithyroid drugs & Propylthiouracil & Potassium iodate & 17 \\
\hline Antidiabetic drugs & Insulin, glibenclamide & Metformin & 17 \\
\hline Hormonal contraceptive & $\begin{array}{l}\text { Levonorgestrel } * * \text {, medroxyprogesterone } * * \\
\text { norethisterone } * *\end{array}$ & Etilnilestradiol & 17 \\
\hline Anticoagulants & Heparin, warfarin & Phenindione & 13,17 \\
\hline Immune suppressors & & Azathioprine, cyclosporin & 17 \\
\hline
\end{tabular}

* Should be used for short periods. Sleepiness should be watched.

$\dagger$ Low doses allowed (100 mg/day).

‡ Immediate postnatal use should be avoided.

$\S$ Risk of intestinal flora alteration and hypersensitivity.
II Use should be avoided in children with hyperbilirubinemia and glucose6-phosphate dehydrogenase deficiency.

I Watch the infant for jaundice.

** Use only 6 weeks after the delivery. 


\section{Galactogogues}

Galactogogues are drugs that help induce or maintain appropriate milk production. Galactogogues may be useful in the following situations: preterm births, maternal or infant disease, adoption or surrogate pregnancy. ${ }^{30}$ These drugs act by blocking dopamine receptors, thus increasing serum levels of prolactin and resulting in higher milk production. Several drugs are used to induce or increase milk production during lactation (Table 8 ).

In clinical practice, drugs used as galactogogues, because of their safety, are metoclopramide and domperidone. There is no evidence that these two drugs stimulate milk production in women with high levels of prolactin or with breast tissue that is not suitable for breastfeeding. However, these drugs work for many mothers of preterm infants. ${ }^{2}$

\section{Metoclopramide}

This drug has a dose-dependent prolactinogenic effect, and is recommended in the dose of 10 to $15 \mathrm{mg} /$ day, given orally, three times a day, for 1 to 2 weeks. According to several authors, $30,32,33,36,37$ it is safe and effective in inducing and maintaining lactation. A small amount crosses into the milk, in concentrations that range from 28 to $157 \mu \mathrm{g} / \mathrm{l}$ in the immediate puerperium. ${ }^{37}$ This drug may produce extrapyramidal effects, such as tremors, bradykinesia and other dystonic reactions, especially in the mother. ${ }^{30}$

\section{Domperidone}

This drug stimulates prolactin secretion, by interfering with the action of dopamine. It has less lipid solubility and a larger molecular weight than metoclopramide, which makes it less permeable to the blood-brain barrier and therefore safer than metoclopramide due to the low risk of extrapyramidal effects. The dose used to induce and maintain lactation ranges from 10 to $30 \mathrm{mg}$, three times a day. 30 According to a randomized double-blind placebo-controlled study, this drug increases milk production by $44.5 \%$ after seven days of use, with milk concentrations of $1.2 \mathrm{ng} / \mathrm{ml} .{ }^{31}$

The sudden withdrawal of these drugs, when combined with galactogogues, may result in significant reduction in milk production. To avoid this, the drug should be gradually withdrawn during some weeks or months. ${ }^{2}$

\section{Other galactogogues}

The use of chlorpromazine and sulpiride as galactogogues is quite restricted due to the potential risk of side effects. In a review article, Winans ${ }^{16}$ suggests that the use of chlorpromazine during lactation should be avoided due to drowsiness and lethargy observed in nursing infants. Aono et al., cited by Winans, ${ }^{16}$ treated 66 women with sulpiride $100 \mathrm{mg} / \mathrm{d}$ on the first seven days of breastfeeding, and observed a significant increase in milk production and in serum prolactin levels, compared to women who received placebo. No adverse effects were described in newborn infants.

Other drugs that act as galactogogues are the growth hormone and the thyrotropin-releasing hormone (TRH), but further clinical experience is required before they can be recommended for such purpose. ${ }^{30}$ Natural products such as fenugreek $^{30}$ (member of the pea family), herbal teas and coconut milk have been used to increase milk production, 36 but no scientific evidence exists that these products are efficacious as galactogogues.

The mechanical stimulation of the areola-nipple complex by infant's suction and milk expression are the most important stimuli for induction and maintenance of lactation. These stimuli promote prolactin secretion by the anterior pituitary gland and oxytocin secretion by the posterior pituitary gland. ${ }^{30}$ Some evidence suggests that with breastfeeding guidance, at least $97 \%$ of women succeed in breastfeeding their infants. ${ }^{38}$ It is therefore the health professional's duty to check whether the breastfeeding technique is correct, that is, if positioning and latch-on are appropriate, whether breastfeeding occurs on demand, or, if the mother is separated from her infant, whether the milk has been expressed manually or mechanically on a regular basis. The use of galactogogues should be reserved for cases in which these measures failed.

\section{Lactation suppressants}

Some drugs are well known for suppressing milk production. As infant growth is directly related to maternal milk production and milk ingestion, the use of any of these drugs may pose a possible risk for weight deficit, especially during the immediate puerperium, moment in which cessation

Table 8 - Drugs used to induce or increase milk production during lactation

\begin{tabular}{llll}
\hline Drug & Dose & Side effects & References \\
\hline Domperidone & $10 \mathrm{mg}$, three times a day & Good tolerance & 30,31 \\
Metoclopramide & $10 \mathrm{mg}$, three times a day & Good tolerance & $30,32,33$ \\
Sulpiride & $50 \mathrm{mg}$, three times a day & Extrapyramidal symptoms, sleepiness & 30,34 \\
Chlorpromazine & $25-100 \mathrm{mg}$, three times a day & Extrapyramidal symptoms, sleepiness & 30,35 \\
\hline
\end{tabular}

Adapted from Biervliet et al. ${ }^{36}$ 
of breastfeeding is mostly critical. Therefore, health professionals should be cautious if any of these drugs has to be actually used, and should delay their introduction for as long as possible (weeks or months). ${ }^{2}$

Table 9 provides a list of lactation suppressants.

Table 9 - Lactation suppressant drugs

\begin{tabular}{ll}
\hline Drugs & Reference \\
\hline Estrogens & $10,17,39$ \\
Bromocriptine & 2,10 \\
Cabergoline & 2,10 \\
Ergotamine & 2,10 \\
Ergometrine & 17 \\
Lisuride & 40 \\
Levodopa & 17 \\
Pseudoephedrine & $2,10,28$ \\
Álcohol & 2,40 \\
Nicotine & 3,13 \\
Bupropion & 2 \\
Diuretics & 17 \\
Testosterone & 10
\end{tabular}

\section{Estrogen}

Estrogen may reduce milk production due to its suppressive effect on prolactin secretion. Therefore, estrogen-containing oral contraceptives should be avoided during lactation, especially during the first three months. The AAP considers estrogen to be compatible with breastfeeding, but other authors disagree. ${ }^{2,6,10}$ In a recent review, Anderson et al. ${ }^{6}$ show that well controlled studies are necessary on the use of low estrogen-containing oral contraceptives during breastfeeding. If these drugs are to be used, infant growth should be monitored. For contraception, only progesterone-containing pills should be used, despite reports of decrease in milk production when progesterone is used too early in the postpartum period, ${ }^{2}$ or another contraceptive method should be used.

\section{Alcohol}

Intake of ethanol ( 1.5 to $1.9 \mathrm{~g} / \mathrm{kg}$ of body weight) may significantly reduce the let-down reflex, and reduce (in the dose of $0.3 \mathrm{~g}$ of ethanol per $\mathrm{kg}$ ) by up to $20 \%$ the ingestion of milk by the infant. ${ }^{13}$ Although the AAP considers alcohol to be compatible with breastfeeding, it should be stressed that only low doses (no more than $0.5 \mathrm{~g}$ of alcohol per maternal body weight per day) should be used due to the low alcohol-dehydrogenase enzyme activity in the nursing infant and to the reported suppressive effect on milk production.

\section{Nicotine}

Although the amount of nicotine excreted into human milk is small, maternal smoking is associated with a decrease in milk production and with early weaning. ${ }^{13}$ However, the AAP considers smoking to be compatible with breastfeeding, due to some studies which showed that breastfed infants of smoking mothers were at a lower risk for respiratory diseases than infants of smoking mothers who were not breastfed. ${ }^{4}$ In addition, a Dutch study showed that the negative effects of intrauterine exposure to tobacco on the cognitive performance of children at the age of nine years were restricted to infants who had not been breastfed. 41 Therefore, breastfeeding combined with maternal smoking is believed to be less harmful to the infant than the use of industrialized milk. However, due to the risk of a lower milk production, infant growth should be closely monitored.

\section{Ergot alkaloids}

These are dopaminergic agonist drugs that prevent the adenohypophysis from secreting prolactin.

Bromocriptine was very much used for suppression of lactation, but after some reports of episodes of hypertension, myocardial infarction and hemorrhagic stroke in puerperal women, the use of this drug was abolished. ${ }^{42,43}$ Therefore, alternatives such as cabergoline, which produces fewer adverse effects, are now available, and are preferred for lactation suppression. ${ }^{44}$ Doses of $1 \mathrm{mg}$ given early on after delivery inhibit lactation completely. When lactation is already established, $0.25 \mathrm{mg}$ is given twice a day for two days. ${ }^{10}$ Colo \& Horta 45 recommend the use of lisuride, an antiparkinsonian agent, for lactation suppression; however, this drug is not available in our setting. Other ergot alkaloids such as ergotamine, used to treat migraine, and ergometrine, widely used as a uterotonic agent right after delivery, can also inhibit lactation. Nevertheless, the AAP4 classifies bromocriptine and ergotamine as "drugs that have been associated with significant effects on some nursing infants and should be given to nursing mothers with caution", not making any reference to other ergot alkaloids.

\section{Pseudoephedrine}

A recent randomized double-blind trial showed a reduction of $24 \%$ in the average milk production in nursing mothers treated with pseudoephedrine in the dose of $60 \mathrm{mg}$ given every six hours, compared to those treated with placebo. ${ }^{28}$ Such inhibition is supposedly due to the reduction of serum prolactin levels. The AAP considers this drug to be safe during breastfeeding, however, due to a new report on lactation suppression, this drug should be used carefully or other decongestants should be chosen, preferably topical ones.

Other drugs that reportedly decrease milk production are diuretics ${ }^{17}$ and testosterone. ${ }^{10}$

\section{Guidelines for the use of drugs during lactation}

Some practical aspects regarding the prescription of drugs to mothers during lactation are:

- assess the necessity for drug therapy. In this case, the consultation between the pediatrician and obstetrician or clinician is very useful. The prescribed drug should have a well known benefit for the condition for which it is being indicated; 
- prefer drugs that have already been studied and which are considered safe for the infant, and which are less often excreted into breastmilk. For instance, paracetamol should be prescribed instead of acetylsalicylic acid; penicillins instead of quinolones;

- prefer drugs that have already been approved to be used in newborns and nursing infants;

- prefer topical or local therapy to oral and parenteral therapy, whenever possible and indicated;

- prefer medications containing only one type of drug, avoiding drug combinations. Example: use only paracetamol instead of combinations containing paracetamol, ASA and caffeine;

- choose medications that are minimally transferred into the milk. For example, sertraline and paroxetine reach lower milk levels than fluoxetine;

- choose medications that are poorly permeable to the blood-brain barrier because they often reach low levels in milk;

- choose medications with high molecular weight, since this considerably reduces their transfer into the milk. E.g.: heparin;

- schedule the administration of the drug to the mother, preventing the period with maximum drug concentration in blood and in breastmilk from coinciding with breastfeeding time. In general, the infant exposure to the drug can be reduced if the drug is used by the mother immediately before or after breastfeeding;

- consider dosing the drug in the infant's bloodstream when there is risk for the child, as occurs in prolonged maternal treatments with the use of antiepileptics;

- instruct the mother to observe the infant in order to identify any side effects, such as changes in eating behavior, in sleep patterns, agitation, abnormal muscle tone and gastrointestinal disorders;

- avoid long-acting drugs, since they are excreted with difficulty by the infant. Example: use midazolam instead of diazepam;

- instruct the mother to express breastmilk in advance and store it in a freezer (for no more than 15 days) to feed her baby in case of temporary cessation of breastfeeding, and suggest regular milk expression in order to maintain lactation.

The careful indication of maternal treatment and the careful selection of drugs often allow breastfeeding to continue uninterruptedly and safely. 46,47

\section{Final remarks}

Although pediatricians do not prescribe drugs to the nursing mother, their opinion about drug safety during breastfeeding is usually sought. Therefore, it is of paramount importance that pediatricians and health professionals be up-to-date with this kind of information.

Special care is required when nursing mothers use drugs that can reduce their milk production. Such drugs should be avoided during lactation; however, if they do have to be used, infant growth should be monitored.
There are frequent questions about the use of galactogogues. We believe their use is seldom necessary in clinical practice, being reserved for special situations such as for mothers of preterm or adopted infants, or mothers of infants from surrogate pregnancy. Even in these cases, or when mothers believe they are producing little milk, guidance regarding breastfeeding techniques (positioning, latch-on, breastfeeding on demand and milk expression) are precious stimuli for appropriate milk production by the mother.

The basic principle for the prescription of drugs to breastfeeding mothers is underpinned by the idea of risk and benefit. The advantages of breastfeeding are enormous for the infant, whereas the risks of most medications are minimal; most of the information about drugs during lactation is based on fixed doses and on short-term studies. Breastfeeding should only be interrupted or discouraged if there is ample evidence that the drug used by the mother can be harmful to the infant, or when there is no information about the drug and the drug cannot be replaced with another one that is harmless to the infant.

In general, nursing mothers should avoid using medications. However, if they are really necessary, a drug that has been widely studied and that is excreted into breastmilk in minimal amounts, or that does not have an apparent risk to the infant's health, should be chosen. By selecting safe drugs and by taking the age of the infant into consideration breastfeeding only has to be discouraged or discontinued when the mother needs drug treatment.

Because of the vast number of pharmacologically active substances available in our setting and due to the misinformation of most physicians about the use of these drugs during breastfeeding, the creation of a hotline (0800) by the Brazilian National Health Surveillance Agency (ANVISA) or by the Brazilian Ministry of Health would be very useful in guiding health professionals about the use of drugs in nursing mothers. However, while this does not happen, health professionals should be instructed to access specialized websites, from which they can obtain up-to-date information about medications and breastfeeding. We suggest visiting the following websites: AAP (www.aap.org/ policy/0063.html) and World Health Organization (WHO) (www.who.int/child-adolescent-health/New Publications/ NUTRITION/BF_Maternal_Medication.pdf).

\section{References}

1. Escobar AMU, Ogawa AR, Hiratsuka M, Kawashita MY, Teruya PY, Grisi S, et al. Aleitamento materno e condições socioeconômico-culturais: fatores que levam ao desmame precoce. Rev Bras Saude Mater Infant. 2002;2:253-61.

2. Hale TW. Medications in breastfeeding mothers of preterm infants. Pediatr Ann. 2003;32:337-47.

3. Howard CR, Lawrence RA. Drugs and breastfeeding. Clin Perinatol. 1999;26:447-78.

4. American Academy of Pediatrics, Committee on drugs. The transfer of drugs and other chemicals into human milk. Pediatrics. 2001;108:776-89.

5. Lamounier JA, Cabral CM, Oliveira BC, Oliveira AB, Júnior AMO, Silva APA. O uso de medicamentos em puérperas interfere nas recomendações ao aleitamento materno? J Pediatr (Rio J). 2002;78:57-61. 
6. Anderson PO, Pochop LS, Manoguerra AS. Adverse drug reactions in breastfed infants: Less than imagined. Clin Pediatr. 2003;42:325-40.

7. Lamounier JA, Chaves RG, Lana APB. Atualização sobre o uso de medicamentos durante amamentação. Sociedad Iberoamericana de Información Científica; 2004. Disponível em: www.siicsalud.com/dato/dat037/004423003.htm. Acessado: 10 de maio de 2004.

8. Ministério da Saúde, Secretaria de Políticas de Saúde, Área Técnica de Saúde da Criança. Amamentação e uso de drogas. Brasília: Ministério da Saúde; 2000.

9. Begg EJ, Duffull SB, Hackett LP, Ilett KF. Studying drugs in human milk: Time to unify the approach. J Hum Lact. 2002;18:323-32.

10. Hale TW. Drug therapy and breastfeeding: pharmacokinetics, risk factors, and effects on milk production. Neoreviews. 2004; 5:e164.

11. Auerbach KG. Breastfeeding and maternal medication use. JOGNN. 1999;28:554-63.

12. Besunder JB, Reed MD, Blumer JL. Principles of drug biodisposition in the neonate: A critical evaluation of the pharmacokineticpharmacodynamic intereface (Pat II). Clin Pharmacokin. 1988; 14:261-86.

13. Ito S. Drug therapy for breastfeeding women. N Engl J Med. 2000;343:118-26.

14. Dicionário de Especialidades Farmacêuticas: DEF 2003/04. 32a ed. Rio de Janeiro: Editora de Publicações Científicas; 2003.

15. Hagg S, Spigset O. Anticonvulsivant use during lactation. Drug Safety. 2000;22:425-40.

16. Winans EA. Antipsychotics and breastfeeding. J Hum Lact. 2001; 17:344-7.

17. World Health Organization/UNICEF. Breastfeeding and maternal medication. Recommendations for drugs in the eleventh WHO model list of essential drugs. 2002. Available at: http:// www.who.int/child-adolescent-health/New Publications/ NUTRITION/BF_Maternal_Medication.pdf. Accessed: May 19, 2004.

18. Winans EA. Antidepressant use during lactation. J Hum Lact. 2001;17:256-61.

19. Bar-Oz B, Bulkowstein M, Benyamini L, Greenberg R, Soriano I, Zimmerman $D$, et al. Use of antibiotic and analgesic drugs during lactation. Drug Saf. 2003;26:925-35.

20. Pietrement C, Maltot L, Santerne B, Roussel B, Motte J, Morville $P$. Neonatal acute failure secondary to maternal exposure to Telmisartan, angiotensin II receptor antagonist. J Perinatol. 2003;23:254-5.

21. Beardmore KS, Morris JM, Gallery EDM. Excretion of antihypertensive medication into human breast milk: a systematic review. Hypertens Pregnancy. 2002;21:85-95.

22. Moretti ME, Lee $A$, Ito $S$. Which drugs are contraindicated during breastfeeding? Practice Guidelines. Can Fam Physician. 2000;46:1753-7.

23. Nice FJ, Snyder JL, Kotansky BC. Breastfeeding and over-thecounter medications. J Hum Lact. 2000;16:319-31.

24. Chin KG, McPherson CE, Hoffman M, Kuchta A, Mactal-Haaf C. Use of anti-infective agents during lactation: Part 2: Aminoglycosides, macrolides, quinolones, sulfonamides, trimethoprim, tetracyclines, chloramphenicol, clindamycin, and metronidazole. J Hum Lact. 2001;17:54-65.

25. Chin KG, Mactal-Haaf C, McPherson CE. Use of anti-infective agents during lactation. Part 1: Beta-lactam antibiotics, vancomycin, quinupristin-dalfopristin and linezolid. J Hum Lact. 2000; $16: 351-8$.

26. Tran JH, Montakantikul $P$. The safety of antituberculosis medications during breastfeeding. J Hum Lact. 1998; 14:337-40.

27. Mactal-Haaf C, Hoffman M, Kuchta A. Use of anti-infective agents during lactation. Part 3 : Antirals, antifungals and urinary antiseptics. J Hum Lact. 2001;17:160-6.

28. Aljazaf K, Hale TW, Ilett KF, Hartmann PE, Mitoulas LR, Kristensen $\mathrm{JH}$, et al. Pseudoephedrine: effects on milk production in women and estimation of infant exposure via breastmilk. $\mathrm{Br}$ J Clin Pharmacol. 2003;56:18-24
29. Del Ciampo LA, Ricco RG, Del Ciampo IRL, Almeida CAN. Fármacos contra-indicados durante o aleitamento materno. In: Del Ciampo LA, Ricco RG, Almeida CAN, editores. Aleitamento materno - Passagens e transferências mãe-filho. São Paulo: Editora Atheneu; 2004. p. 95-8.

30. Gabay MP. Galatogogues: Medications that induce lactation. J Hum Lact. $2002 ; 18: 274-9$.

31. Da Silva OP, Knoppert DC, Angelini MM, Forret PA. Effect of domperidone on milk production in mothers of premature newborns: a randomized, double-blind, placebo-controlled trial. CMAJ. 2001;164:17-21.

32. Budd SC, Erdman SH, Long DM, Trombley SK, Udall JN. Improved lactation with metoclopramide: a case report. Clin Pediatr. 1993;32:53-7.

33. Banapurmath CR, Banapurmath S, Kesaree N. Successful lactation in surrogate mothers. Indian J Paediat. 1993;60: 693-743.

34. Hallbauer U. Sulpiride (Egonyl)- use to stimulate lactation. S Afric Med J. 1997;87:774-5.

35. Nemba K. Induced lactation: a study of 37 non-puerperal mothers. J Trop Paediat. 1994;40:240-2.

36. Biervliet PF, Maguiness SD, Hay DM, Killick SR, Atkin SL. Case report: Induction of lactation in the intended mother of a surrogate pregnancy. Hum Reprod. 2001;16:581-3.

37. Kauppila A, Kivinen S, Ylikorkala O. A dose response relation between improved lactation and metoclopramide. Lancet. $1981 ; 1: 1175-7$.

38. Neville MC. Anatomy and physiology of lactation. Pediatr Clin North Am. 2001;48:13-34.

39. Treffers PE. Breastfeeding and contraception. Ned Tijdschr Geneeskd. 1999;143:1900-4

40. Neville MC, Walsh CT. Effects of drugs on milk secretion and composition. In: Bennett PN, ed. Drugs and human lactation. Amsterdam, The Netherlands: Elselvier; 1996. p. 15-46.

41. Batstra L, Neeleman J, Hadders-Algra M. Can breast feeding modify the adverse effects of smoking during pregnancy on the child's cognitive development? J Epidemiol Community Health. 2003;57:403-4.

42. Hopp L, Haider B, Iffy L. Myocardial infarction postpartum in patients taking bromocriptine for the prevention of breast engorgement. J Cardiol. 1996;57:227-32.

43. Rayburn WF. Clinical commentary: The bromocriptine (Parlodel) controversy and recommendations for lactation suppress. Am J Perinatol. 1996;13:69-71.

44. De Groot AN, Van Dongen PW, Vree TB, Hekster YA, Van Roosmalen J. Ergot alkaloids. Current status and review of clinical pharmacology and therapeutic use compared with other oxytocics in obstetrics and gynaecology. Drugs. 1998;56:523-35.

45. Colo JAS, Horta MTN. Inhibición de la lactancia con lisurida: evaluación clínica. Ginecol Obstet Méx. 1994;62:31-4.

46. Bagatin AC, Brito LMO, Doria EGC, Lamounier JA, Vieira GO, Serva VMB. Amamentação e uso de drogas. In: Rego JD, editor. Aleitamento materno. Rio de Janeiro: Atheneu; 2001.

47. Lamounier JA, Doria EGC, Bagatin AC, Vieira GO, Serva VMB, Brito LMO. Medicamentos e amamentação. Revista Médica de Minas Gerais. 2000;10:101-11.

Corresponding author

Joel Alves Lamounier

Faculdade de Medicina, Universidade Federal de Minas Gerais.

Avenida Alfredo Balena, 190

CEP 30130-100 - Belo Horizonte, MG

Brazil

Phone: +55 (31) 3248.9300

E-mail: joel@reitoria.ufmg.br 